\title{
The Effect Of Blog Trustworthiness, Product Attitude, And Blog Involvement On Purchase Intention
}

Wei-Li Wu, Ph.D., Ching Yun University, Taiwan

Yi-Chih Lee, Ph.D., Ching Yun University, Taiwan

\begin{abstract}
Consumers value the advice of others when they are shopping online. Therefore, some high pageview bloggers could have a great influence on a consumer's shopping decision. Blog marketing is a new communication tool. "Blog trustworthiness", "product attitude" and "blog involvement" were the three independent variables used in this study to investigate the aspect of purchase intention. This study found that blog involvement had a significant influence on purchase intention. This result contributes concrete suggestions to enterprises when they are dealing with blog marketing.
\end{abstract}

Keywords: Blog Trustworthiness; Product Attitude; Blog Involvement on Purchase Intention

\section{INTRODUCTION}

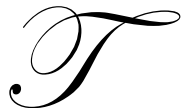

he use of blogs has become an indispensable part of life for many people. In Taiwan, blogs have become the fastest and most convenient channel for following world trends, in addition to a wide range of media forms. In 1999, the "web log" (or blog) began to be widely used in Taiwan. Over the years, from the originally perceived idea as a personal tool to record daily life, blogs have developed into a new media force. When office workmates are planning to group purchase food, when some girls are about to drink afternoon tea, or before online buyers place an order for certain products, they are all inclined to search for related blogs on the Internet. Smart bloggers with an amazing degree of popularity, may attract visitors with more pageviews in a single day than even the largest newspaper circulation. Therefore, their influence on other netizens may be turned into a business opportunity and become the hot market that the major stores seek to get into. The Information Industry Association (2007) identified a consumer's online shopping process as six steps: demand arising, information search, information evaluation, transaction confirmation, consumer service, and comment. In the process of finding information, consumers most frequently rely on product information through search engines, reference entries and shopping sites. Meanwhile, for assessing information and posting comments, most reviewers will mainly adopt blogs, shopping communities, BBS stations and professional review websites. Through blogs, consumers have a platform for a wide range of contact with other consumers and the voice of one individual consumer may be expanded and spread out across the Internet. When consumers get positive feedback from a blog platform, they are more likely to become more actively involved. Laurent and Kapferer (1985) believed that involvement is composed of four dimensions: pleasure value, symbolic value, interest, and perceived risk; and different degrees of involvement will affect the information collecting, processing, and decision-making. In this study, the degree of blog involvement was included as a variable to investigate whether consumers with higher blog involvement are more easily affected by online reviews and will thus change their purchase intention, whilst searching for information through the emerging media blog.

The report by BIG research (2006) pointed out that a blog is an important source of online content and their survey of consumer intention and behavior suggests that $87 \%$ of consumers will search for related product information and other users' comments on the Internet before purchase. Technorati's (2008) report concerning global blog status showed that $80 \%$ of bloggers had posted comments on some brands or products, of which $37 \%$ frequently write blogs of this kind. The report also pointed out that while browsing blogs, consumers are likely to express their disagreement on information given by different blogs. In March 2010, the Nielsen Company did a survey of online shopping, whose results suggested that among Taiwan's online respondents, cosmetics/nutritional supplements are one of the top five online purchase goods, accounting for $26 \%$. In addition, the influence of word of 
mouth is significant, especially from friends and family. Over $60 \%$ of the respondents stated that they trusted recommendations from friends when making purchase decisions. On the other hand, the word of mouth of online media also plays an important role. $41 \%$ of online respondents in Taiwan admitted that they trusted most of the product reviews from the Internet and $31 \%$ relied on online forums. $14 \%$ of them trusted influential bloggers while making purchase decisions. The proportion of Taiwanese purchasers who trusted online discussion zones and bloggers ranks as second in the world. Among those products for which Taiwan shoppers tend to refer to the online comments before purchase, cosmetics (42\%) ranked in the top three; nearly half of consumers claimed that they would not purchase certain products without reference to online comments, with drugs accounting for $28 \%$. Apparently, online comments play a critical role in a customer's purchase decision-making (Nelson, 2010). Thus, how to manage and utilize online reviews has become an important issue for manufacturers.

Consumers value highly the evaluation of other users while shopping, thus high pageview bloggers may have a great influence on a consumer's purchase decision-making. These bloggers are seen as opinion leaders with plenty of opportunities for product advertising and endorsement. This indicates that rather than the traditional direct trust toward brands or products, consumers' purchase decision-making now relies on their trust of bloggers, which can turn into trust for a product, resulting in so-called trust transfer. Stewart (2003) held that trust can be transferred through different channels in the Internet environment. Today, many popular bloggers can attract a large number of loyal viewers, and thus have the characteristic of trustworthiness. Therefore, this study aimed to investigate the effect of consumers' trust of blogger recommendation on their purchase intention.

With the advance in biotechnology and medical technology, as well as the increase in the world's aging population, consumers' awareness of aging prevention is rising and, with their demand for cosmetic products increasing, the beauty industry has become a key emerging industry in recent years. For the beauty industry, consumers require products to be perfectly safe, fast, and significantly effective, making efficacy products (such as cosmaceuticals, medical cosmetic products) profitable and prosperous in today's cosmetics market. According to the market research firm Kline \& Company's data, in 2008 the scale of the global cosmaceutical market reached 57 billion U.S. dollars. Europe was the world's largest regional market with the market scale of 19.95 billion U.S. dollars, accounting for 35\% of the overall market, followed by Asia, whose market scale reached 13.68 billion U.S. dollars, accounting for $24 \%$ of the market as a whole. Currently the United States, Europe, and Japan are still the main markets, but China, Latin America, Russia, India and other developing countries have been catching up with a double-digit growth rate in recent years, and with endless market potential (HSU, 2010). As the scholars O'Guinn and Faber (1989) indicated, each consumer's consumption behavior is not necessarily exactly the same as that of others. Due to the medical profession's involvement in the medical cosmetic industry, while selecting these products, consumers are inclined to take into consideration several factors that are different from general consumers. Hence, this study included consumers' product attitude as one research factor.

To sum up, information from different blogs may have a further effect on online shoppers; bloggers may even lead consumers to do multiple shopping or even manipulate consumers' purchase intentions and thereby bring about their purchase of products or services on other blog pages. For the rapid rise in the self-financed cosmetic medicine blog market, this study investigated the effect of blog trustworthiness, product attitude and blog involvement on purchase intention of medical and beauty products.

Based on the mentioned research background and motivation, the purposes of this study were as follows:

1. To learn the degree of influence that blog trustworthiness has on a consumer's purchase intention.

2. To explore the degree of influence that a consumer's product attitude has on purchase intention.

3. To explore the level of influence that a consumer's blog involvement has on purchase intention.

4. To explore whether blog trustworthiness, product attitude and blog involvement have an interactive effect on each other and which thereby affect a consumer's purchase intention.

\section{LITERATURE REVIEW}

\section{Blog Trustworthiness}

Regarding trust, social psychologists advocated that the trust relationship may occur interpersonally or inter-organizationally, emphasizing individual behavior with consistency and predictable well-intentioned behavior (Doney, Cannon, and Mullen, 1998). In addition, trust can be used as an important construct, property or mechanism 
to interpret interpersonal behavior under social institutions (Zucker, 1986). Fukuyama, (2001) viewed trust as the expectation of regular, honest, and cooperative behavior based on commonly shared norms and values. From the perspective of transaction cost, Williamson (1985) stressed that bounded rationality and opportunism on both transaction sides lead to the calculation of cost and profit arising in the transaction process for the transaction sake, so trust is nothing but conceived in its calculative aspect or social institutions.

Blog marketing is a newly-formed marketing pattern in recent years, owing to the development of information technology, given that consumers were tired of the generally-used mass marketing techniques and lacked trust in the authenticity of goods or services. Blogs are a new sharing method for average consumers, where the bloggers can interact with each other through direct dialogue on an unofficial basis and thus provide viewers with a situational description of daily life that is closely linked with their attention and interest. In particular, some celebrity blogs with a high browsing rate have attracted companies to inquire about cooperation feasibility in the hope that a new type of business opportunity can be created. Shneiderman (2000) pointed out that recommendations from past and present users or from a third party can help to promote consumer trust towards the website. Briggs, et al. (2002) indicated that what is most important is that the website design should look and feel appealing and that information conveyed should be reliable and trustworthy, with a clear and real service, including links to relevant alternative opinions or products. Wu et al. (2008) stated that online shoppers' trust toward certain shopping websites may affect their adoption of the website system. In addition, through increasing communication with other online shoppers, websites can promote consumer trust as well as their assessment of the shopping sites in terms of perceived ease of use and perceived usefulness and, therefore, enhance consumers' willingness to use the site.

\section{Product Attitude}

As the Taiwanese medical beauty industry has been booming for nearly a decade, plus the fact that the medical care of this kind is usually not covered by insurance, all medical institutes and biotechnology firms have striven to make more investment for higher profits. Based on consumers' knowledge of product quality before and after purchase, Darby and Kami (1973) distinguished products as search goods, experience goods and credence goods. Search goods refer to those products whose attributes can be obtained through information searching before purchase or consumption. In the case of experience goods, essential product attributes cannot be known through information searching before purchase or consumption, (or if they can, at high cost). Credence goods are those products where consumers cannot determine the product quality or attributes even after purchase and consumption. These include education, health care and consulting, which are highly professional services, or antibiotics contained in food, heavy metals and pesticide residues, etc., whose attributes are hard to ascertain unless at high cost or by turning to experts.

Chun-Hsin Zhang (1986) defined attitude as an individual's persistent and consistent tendency toward people, matters or surrounding conditions, which can be predicted by individuals' explicit behavior. Ajzen and Fishbein (1980) stated that attitude is a certain observation of a subject's like-or-dislike evaluation and state, views based on the cognitive appraisal of matters or a lasting and stable evaluation and preferences. Ajzen and Fishbein (1980) further classified attitude with two concepts: "attitude toward the behavior" and "attitude toward the object". The former refers to an individual's attitude toward behavior; for example, helping others is the right thing. The latter refers to an individual's attitude toward people, matters or issues, such as the opinion that goods for sale online are cheaper. Attitude may directly affect purchase intention, and also affect purchase behavior through other people's viewpoints and the external environment. If a consumer's attitude toward advertising and a product is positive, coupled with the customer's demand for the product, the purchase intention may then come into being.

\section{Blog Involvement}

Involvement described in this study refers to the degree of blog involvement. However, Laurent and Kapferer (1985) pointed out that the concept of involvement has been widely used as a measurement of consumer attitude and behavior. Yet owing to a wide range of stimuli, such as situations, products, media, or personal experience, there are devised product involvement, purchase involvement, media involvement and situational and enduring involvement, with correspondingly extended applications. Based on consumers' behavior toward certain involvement objects, Zaichkowsky (1986) divided involvement roughly into advertisement involvement, product involvement and purchase-decision involvement. (1) Advertising involvement: refers to consumer's attention level and corresponding reaction to advertisements on the basis of personal factors, such as demand, importance, value, 
and interest, along with external factors, such as communication source, communication content, and stimuli, as well as purchase and consumption; (2) Product involvement: consumer's attachment and reaction differ for different product types, brands and qualities; (3) Purchase decision-making involvement: consumer's different behavior reactions with regard to information search, price, brand selection, time, alternatives and decision-making for the purchase purpose.

\section{Purchase Intention}

Purchase intention means a certain transaction occurs after consumer's overall evaluation of the product, resulting from an emotional reaction to the attitude object's certain behavior. Reynolds and Wells (1977) distinguished consumers' characteristics between descriptive and predictive, and concluded that it is more accurate to predict purchase behavior through purchase intention rather than through preference. Therefore, before the actual purchase behavior, the measurement of purchase intention can act as a prediction variable of actual behavior. Morwitz and Schmittleit (1992) proposed that consumers' purchase intention can be used to predict actual purchase behavior. Marketing staff have supported that purchase intention is the most accurate prediction factor of purchase behavior. Therefore, purchase intention is often taken as an important variable for predicting the future actual behavior. For example, the wish to immediately purchase is strong purchase intention, to purchase in one year is moderate, and to purchase after three years is weak. Dodds et al. (1991) defined purchase intention as the possibility of consumers attempting to purchase the product.

\section{METHODS}

\section{Research Framework and Hypotheses}

After the exploration of relevant literature, this study aimed to investigate the effect of a consumer's blog trustworthiness, product attitude and blog involvement on their purchase intention. There were few previous studies committed to a blog's influence on consumption behavior of medical and beauty products. To scrutinize a blog's impact on the purchase of medical and beauty products, this study was conducted from three dimensions: (1) how much the degree of consumer's trust towards a blog will influence purchase intention; (2) similarly, how a consumer's blog involvement will influence the purchase of the products described in the blog; in addition, the consumer's attitude toward medical and beauty products also has a certain impact on the purchase. Summing up, this research proposed the following framework, as shown in Figure 1:

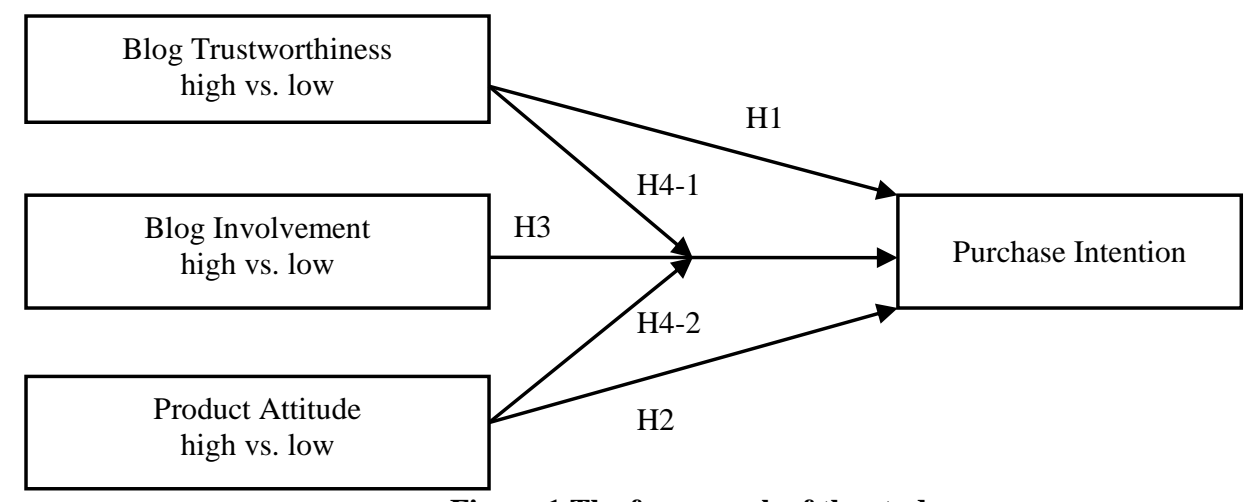

Figure 1 The framework of the study

This study aimed to explore the effect of blog trustworthiness, product attitude and blog involvement (independent variable) on purchase intention (dependent variable). Based on the research framework in Figure 1, this study proposed the following research hypotheses:

Gefen (2000) argued that when a consumer's trust toward a shopping site increases, their purchase intention will, accordingly, increase, as the shopping site not only satisfies the traditional buyer-seller relation, but also reduces the risk of online shopping. Hence, this study proposed the hypothesis:

H1: The higher the blog trustworthiness, the higher the consumer's purchase intention. 
The research of Miyake and Norman (1979) suggested that a consumer's knowledge allows them to put forward demands and to judge the product quality. Chung et al. (2008) claimed that the quality of the product information provided by online intermediaries has a positive impact on product attitude. Hence, the hypothesis as follows:

H2: The higher a consumer's product attitude, the higher the purchase intention.

$\mathrm{Wu}$ (2008) indicated that as far as involvement is concerned, online information recipients are significantly differences in terms of either their willingness to believe online consumption rumors or their own consumption behavior and intention. McQuarrie and Muson (1987) assumed that since the perceived importance and interest is an important factor affecting consumers' involvement, when a consumer' needs, importance and interest in certain information or a product is higher, their involvement will be higher. Therefore, this study hypothesized that:

H3: The higher a consumer's blog involvement, the higher the purchase intention.

Park and Lee (2008) stated that in the case of low involvement with the reviews of other online consumers, consumers themselves are inclined to develop comprehension of information through the peripheral path. In other words, they pay more attention to the clues of non-product-features rather than carefully examining the reviews of the product itself or to assess the credibility of information sources. In addition, Maheswaran and Meyers (1990) pointed out that with different degrees of involvement, information (be it positive or negative) will basically have different effects on consumer attitude. When in a high involvement situation, the consumer's comprehension of related issues will be more in-depth. However, according to Brucks's (1985) research, high subjective knowledge does not necessarily go with equally high objective knowledge. The correlation between the two is not significant, as the knowledge that consumers objectively assume they master is not equivalent to the practically correct knowledge. Subjective knowledge is not only affected by objective knowledge, but also by the degree of a consumer's confidence in their product knowledge. Rudell (1979) made the comparison between objective knowledge and subjective knowledge of information dealing and concluded that objective knowledge is conducive to consumers' thoughtful decision-making. Raju, Lonial and Mangold (1995) assumed that objective knowledge has an influence on information searching and the acceptance of product attributes. Even with a low product attitude and low blog trustworthiness, consumers with higher blog involvement may still find it easier to collect information through other online shoppers' reviews and thereby generate different purchase intentions. This study suggests that consumer purchase intentions may be under the influence of the interaction of subjective and objective knowledge so, in practice, the factors that have an influence on consumer purchase intentions should be composed of the interaction of different factors. Therefore, this study made the following exploratory hypothesis, assuming that blog trustworthiness, product attitude and blog involvement may interact with each other, thereby affecting consumer purchase intentions.

H4-1: The interaction between different blog involvement and blog trustworthiness will result in different purchase intentions.

H4-2: The interaction between different blog involvement and product attitude will result in different purchase intentions.

\section{Questionnaire Design and Pilot Study}

The research adopted a structured questionnaire as the approach to data collection, regarding "trustworthiness", "product attitude", "involvement" and "purchase intention", with blog product browsers targeted. The questionnaire design was modified from the literature of Wu Yaxin, Zaichkowsky and other scholars. In addition to the literature as the main source, blog users' characteristics were also included as one item of the scale. The Likert Scale was adopted to measure the degree of the agreement with scale items, where "strongly agree", "agree", "neutral", "disagree" and "strongly disagree" were respectively represented by 5, 4, 3, 2, and 1 as the measured values.

\section{Credibility and Validity}

In order to test the consistency of the scale, 30 eligible students from Ching Yun University were selected for the pilot study and reliability analysis and, consequently, the items with a low correlation coefficient were 
deleted. The modified questionnaire contained eight questions on "trustworthiness", 10 on "product attitude", 10 on "blog involvement", and five on "purchase intention". The Cronbach's $\alpha$ was $0.725,0.762,0.972$, and 0.714, respectively, and the Cronbach's $\alpha$ of the overall construct was 0.871 , suggesting that the value of Cronbach's $\alpha$ for each was greater than 0.7 , and thus all the constructs of the questionnaire were credible. The scale of this study was to conduct an item analysis in accordance with the data obtained. First, the extreme-group comparative analysis was undertaken, which meant all respondents were ranked in descending order based on their total scores in the scale, the first $27 \%$ being set as the high-score group, while the last $27 \%$ were the low-score group. A comparison was then made between the two groups with a t-test, to calculate the significance testing for the two groups' mean difference for each item, also known as the critical ratio (CR value). When the CR is significant ( $p<0.05)$, it suggests that the item can discriminate reactions of differential respondents. In this study, the CR values of the items ranged from 7.875 to -10.877 , all of which reached the level of significance $(\mathrm{p}<0.05)$, indicating that all the items had a high discrimination.

\section{Sampling Design and Respondents}

In this study, samples were collected through online questionnaires, aimed at exploring consumption motivation and the behavior of current consumers. The respondents of this study were mainly those who had used a blog web service and an electronic bulletin board. Questionnaires were released by means of convenience sampling, i.e. releasing to those who had used a blog service or BBS (Bulletin Board System)users and, meanwhile, posting online subjects on blog websites and BBS, with the intention of attracting users to make replies. The research results were promised as a feedback for enhancing the rate of replying. In both methods above, there was a prior selection for the main respondents, that is, those who had used a blog service and an electronic bulletin board. The questionnaires completed for this study were 500 in total, (70 invalid, and 430 valid), with a validity rate of $86 \%$. After encoding the valid questionnaires, this study decided on the appropriate statistical analysis using the SPSS12.0 statistical software.

\section{RESULTS}

\section{Analysis of Sampling Structure}

With regard to the gender distribution, of the 430 valid questionnaires, 206 were male respondents, accounting for $48 \%$, and 224 were female, 52\%, suggesting that, in this study, the number of female respondents surpassed males. For age distribution, the main group, respondents between 21-30 years old, accounted for $48.3 \%$ of the valid questionnaires, followed by those 31-40 years old $(30.1 \%)$. This indicated that the respondents who completed the questionnaire were mostly aged 21 to 30 and most of them were young consumers who were likely to search for related knowledge on the Internet. As to educational background, graduates from tertiary institutions accounted for the majority, $65.12 \%$ of the valid samples, followed by high school graduates $(23.49 \%)$. graduates and above accounted for $9.53 \%$, while junior high and below were just $1.86 \%$. In the profession section, the respondents were simply divided into students and workers, with students taking up $28.1 \%$, and $71.9 \%$ with a fixed job. For monthly income, those who earned NT 10,001 to NT 20,000 per month accounted for $38.37 \%$. This was followed by NT 20,001 to NT 30,000, accounting for $28.15 \%$, less than 10,000 (22.09\%), NT 30,001 to NT 40,000 (10.23\%) and NT 40,001 to NT $50,000(1.16 \%)$.

\section{Testing the Effect of Independent Variables on Purchase Intention}

The study predicted that blog trustworthiness, product attitude, and blog involvement had an effect on purchase intention, and then conducted tests on the hypotheses through a variance analysis, the results being shown in Table 1. The overall model fit was significant $(\mathrm{F}=3.472, \mathrm{p}=0.001)$. Blog trustworthiness had no significant influence on purchase intention $(\mathrm{F}=0.584, \mathrm{p}=0.445)$ and, thus, Hypothesis 1 was not valid. Product attitude had no significant influence on purchase intention either $(\mathrm{F}$ value $=1.599, \mathrm{p}=0.207)$ and, thus, Hypothesis 2 was not valid. Blog involvement had a significant influence on purchase intention $(F=9.538, p=0.002)$ and, thus, Hypothesis 3 was valid. As Hypothesis 4 of this study was exploratory inference, it was assumed that a confidence level below $90 \%$ was statistically significant. The test of the interaction effect between blog involvement and blog trustworthiness showed $\mathrm{F}=3.255, \mathrm{p}=0.072$, suggesting the existence of the interaction between the two independent variables (with a confidence level of 90\%) and, thus, Hypothesis 4-1 was valid. Since there existed the interaction between blog involvement and blog trustworthiness, a main effect testing was subsequently conducted. 
In the case of low involvement, the result of the ANOVA test showed $F=2.867, p=0.092(<0.1)$. As shown in the interaction diagram (Figure 2), in the case of low blog involvement, higher trustworthiness leads to significantly higher purchase intention compared with lower blog trustworthiness. In the case of high blog involvement, the ANOVA test was $\mathrm{F}=0.927$ and $\mathrm{p}=0.337$, the result not being significant. This indicated that in the case of high blog involvement, blog trustworthiness had no significant effect on consumer purchase intentions. Moreover, the test for the interaction effect between blog involvement and product attitude showed $\mathrm{F}=3.140, \mathrm{p}=0.077$, suggesting the existence of an interaction between the two independent variables (with the confidence level of 90\%) and, thus, Hypotheses 4-2 was valid. Since there existed the interaction between blog involvement and product attitude, main effect testing was conducted subsequently. In the case of low involvement, the result of the ANOVA test showed F $=3.930, \mathrm{p}=0.049(<0.1)$. As shown in the interaction diagram (Figure 3 ), in the case of low blog involvement, higher product attitude leads to a significantly higher purchase intention compared with lower product attitude. Meanwhile, in the case of high blog involvement, the ANOVA test was $\mathrm{F}=0.975$ and $\mathrm{p}=0.325$, the result not being significant, indicating that in the case of high blog involvement, product attitude had no significant effect on consumer purchase intentions.

Table 1 Analysis of effect of blog trustworthiness, product attitude and blog involvement on purchase intention

\begin{tabular}{lccccc}
\hline \multicolumn{1}{c}{ Variables } & $\begin{array}{c}\text { Type III Sum of } \\
\text { squares }\end{array}$ & df & $\begin{array}{c}\text { Average sum of } \\
\text { squares }\end{array}$ & F value & P value \\
\hline overall & 27.344 & 7 & 3.906 & 3.472 & $0.001^{*}$ \\
intercept & 5046.352 & 1 & & 4485.315 & 0.000 \\
blog trustworthiness & 0.658 & 1 & & 0.584 & 0.445 \\
product attitude & 1.799 & 1 & 1.599 & 0.207 \\
blog involvement & 10.731 & 1 & 9.538 & $0.002^{*}$ \\
blog trustworthiness*blog involvement & 3.662 & 1 & 3.255 & $0.072^{*}$ \\
product attitude*blog involvement & 3.533 & 1 & 3.140 & $0.077^{*}$ \\
\hline
\end{tabular}

\section{${ }^{*} \mathrm{P}<0.1$}

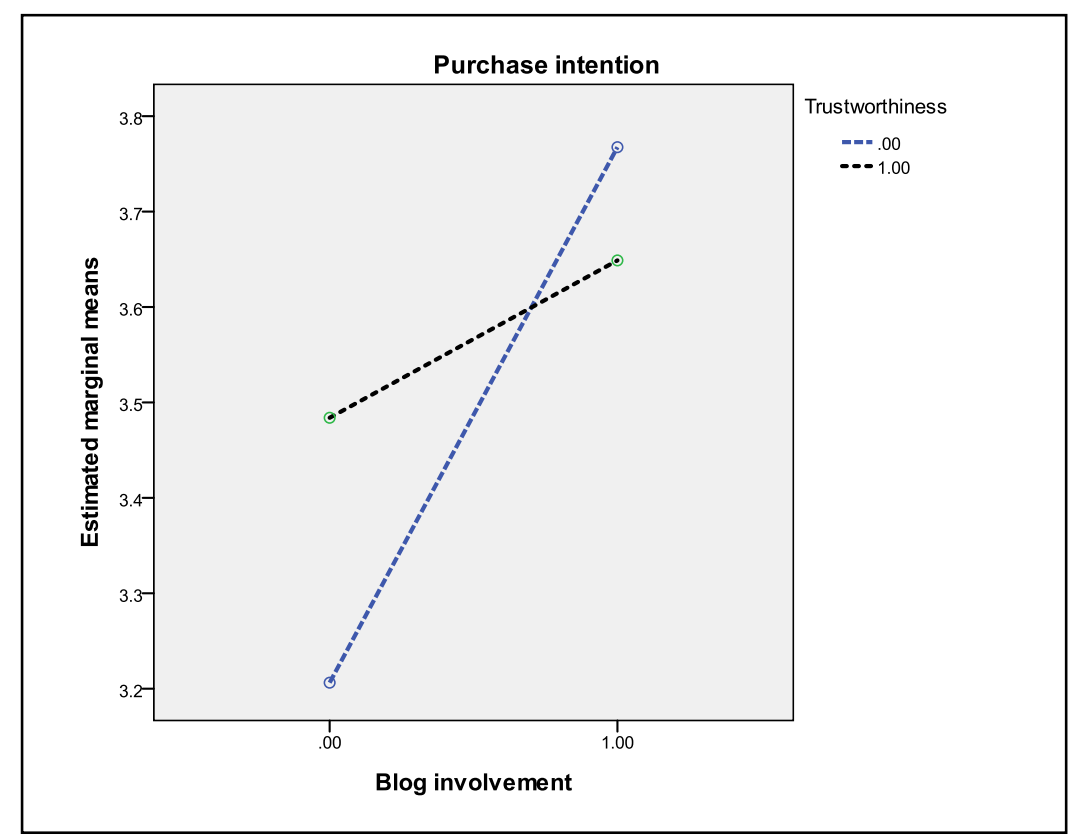

Figure 2 Estimated marginal means of the disturbance variable (blog trustworthiness) on purchase intention 


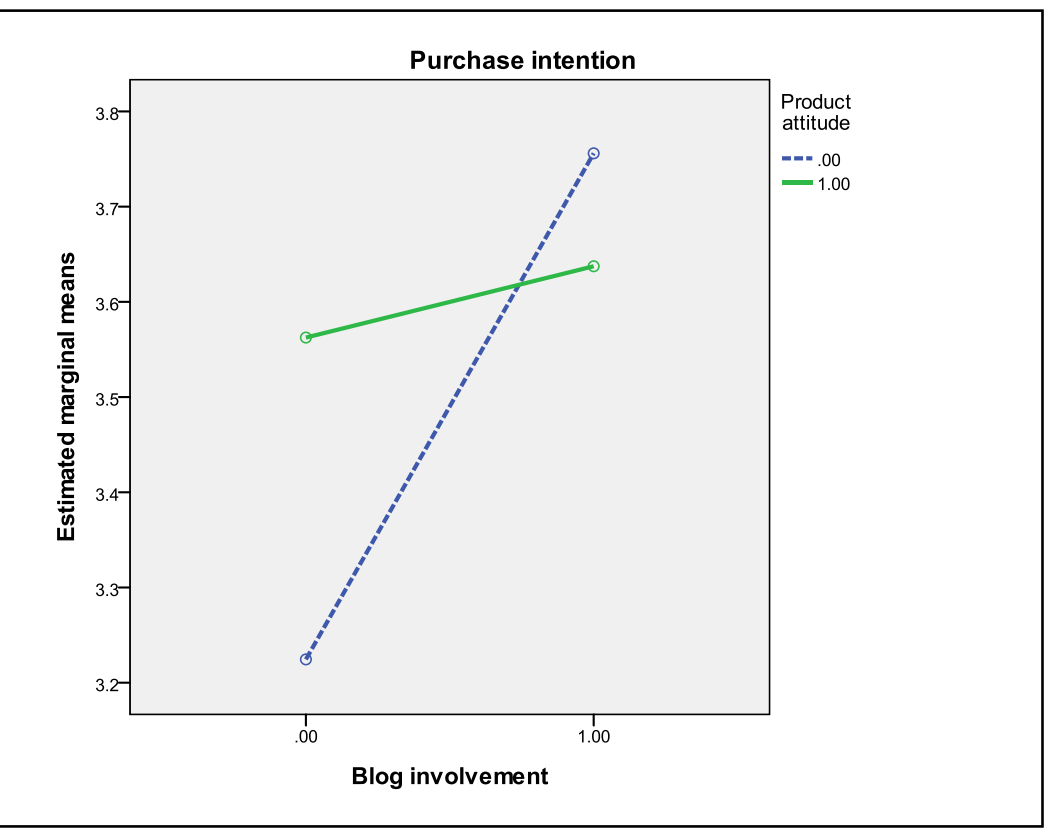

Figure 3 Estimated marginal means of the disturbance variable (product attitude) on purchase intention

\section{DISCUSSION AND CONCLUSION}

\section{Research Findings and Discussion}

The empirical results suggest that consumers' blog involvement has a significant influence on purchase intention, and further details are described, as follows.

\section{The effect of trustworthiness on purchase intention (H1)}

As shown in the research results, the different levels of trustworthiness do not affect consumer purchase intentions for medical and beauty products and, therefore, the hypothesis was invalid. In this study, trustworthiness referred to viewers' trust toward product introduction by the blogger. Nevertheless, owing to the professional characteristics of medical and beauty products, even consumers with a high level of trust toward a blog may still harbor some reservations while browsing the reviews in terms of the product expertise and, further, may not find it entirely agreeable. Hence, purchase intention is not promoted.

\section{The effect of product attitude on purchase intention (H2)}

Since there are abundant brands of medical and beauty products currently on the market, consumers may feel confused when faced with so many brands. In addition, medical and beauty products involve pharmaceutical ingredients, and consumers commonly lack such expertise. Thus, consumers' attitude toward products of this kind cannot influence their purchase intention. Therefore, this hypothesis is not valid.

\section{The effect of blog involvement on purchase intention (H3)}

Brooker (1981) claimed that the risk of product purchase is an antecedent of involvement and, thus, he assumed that in order to reduce the risk perception, consumers would try to collect product information. Hence, in the case of high involvement, their attention would be placed on the product information, and their association will be affected by the information content, i.e. when the information can cause a positive association, viewers are likely to generate positive attitude. Thus, higher blog involvement results in active participation in the discussion concerning blog contents, and consumer purchase intentions will be enhanced through the interaction between 
viewers and bloggers concerning medical and beauty products. Hence, the hypothesis (H3), that consumers' blog involvement has an influence on purchase intention, is valid.

\section{The interactive effect of trustworthiness and blog involvement (H4-1)}

As shown in the research results, when facing information about medical and beauty products provided by blogs with which consumers have different levels of involvement, blog trustworthiness will affect their purchase intention. Consumers' high involvement with blog usage behavior means that they tend to obtain relevant information from interaction with other viewers. Therefore, even with a low level of trustworthiness, other viewers' positive evaluation of medical and beauty products, plus the expertise characteristic of medical and beauty products and consumer's entry difficulty with product knowledge, consumers may still produce a high purchase intention.

\section{The interactive effect of product attitude and blog involvement (H4-2)}

According to the research results, when facing information about medical and beauty products provided by blogs with which consumers have different levels of involvement, product attitude will affect their purchase intention. When the consumer is highly involved with blog usage behavior, they will more frequently gather relevant product knowledge through blog interaction. Therefore, those who originally hold a negative attitude toward medical and beauty products will be influenced by other users' highly positive reviews and will change their product attitude, thereby stimulating higher purchase intentions.

\section{Practical Suggestions}

This study took medical and cosmetic products as an example and the research results showed that consumers' blog involvement has a positive impact on purchase intention as consumers with a higher involvement are more likely to acquire product-related information through the discussions between blog viewers. Therefore, while taking advantage of new marketing channels to enhance the brand awareness of medical and beauty products, firms should not only convey positive information through popular blogs and pilot user blogs, but also value the evaluation of common users. According to Nielsen (2007), with regard to consumers' attitude towards 13 different advertising forms (ranging from traditional newspaper, TV advertisements, to brand websites, as well as the reviews written by consumers), Taiwan's online consumers value "consumer suggestions" most highly, up to $91 \%$. This is followed by brand websites and consumers' opinions on the websites, both at $75 \%$. The results of this study also showed that when the consumer is highly involved with a blog, even though the original blogger may have a low attitude toward the medical and beauty product, or the consumer's trust of the blogger is low, through the evaluation discussion between users and consumer recommendations, a consumer's purchase intention can still be promoted. Hence, it is concluded that before consuming a certain product or service, recommendations from others are still the most trusted information source. Firms should be highly aware that bad news travels and there is nothing faster than the speed of bad news spreading. Therefore, only those products and services of a high quality are capable of gaining a positive assessment and are conducive to further business opportunities.

\section{Research Limitations and Suggestions}

Due to time and cost constraints, this study adopted the convenience sampling method, and placed an online questionnaire on the questionnaire version and cost-saving version of BBS, as well as other online channels. Consequently, students and workers (21-30 years old) constituted the majority of the respondents, and the research result can merely be representative of young people's viewpoints on purchase intention through blog information, rather than representing the purchase intention across all ages. Therefore, it is recommended that future research should conduct an age-based study and adopt paper questionnaires to stratify and complete samples for the purpose of the generalization of the research results. Furthermore, this study believes that an individual's behavior is subject to a number of factors, and this study took into account merely blog trustworthiness, product attitude and blog involvement. Therefore, it is suggested that future researchers on blog information or related issues should add more factors that affect behavioral intentions in order to investigate what factors have the most significant effect and provide a reference for the practical realm. 


\section{AUTHOR INFORMATION}

Wei-Li Wu is an Assistant Professor in the Department of International Business at Ching Yun University. He received his $\mathrm{PhD}$ in International Business from the College of Management at National Chi Nan University in Nantou, Taiwan. His research interests include knowledge management, international business management and organizational behavior. E-mail: wuweili0709@yahoo.com.tw

Yi-Chih Lee received her PhD in Business Administration from the Fu Jen Catholic University of Taipei, Taiwan. Currently, she is an Assistant Professor in the Department of International Business at Ching Yun University. Her research interests include health industry management, data mining and customer relationship management. E-mail: lyc6115@ms61.hinet.net. Corresponding author.

\section{REFERENCES}

1. Ajzen, I., \& Fishbein, M. (1980). Understanding attitudes and predicting social behavior. Englewood Cliffs, NJ: Prentice-Hall.

2. $\quad$ Briggs, P., Burford, B., Angeli, A. D. \& Lynch, P. (2002). Trust in Online Advice. Social Science Computer Review, 20, 321. Accessed from: http://ssc.sagepub.com/cgi/content/abstract/20/3/321

3. Brooker, G.P. (1981). A Comparison of the Persuasive Effects of Mild Humor and Mild Fear Appeals. Journal of Advertising, 10(4), 29-40.

4. Brucks, M. (1985). The Effects of Product Class Knowledge on Information Search Behavior. Journal of Consumer Research, 12(1), 1-16.

5. Chung, S., Han, I., \& Choi, M. (2008). The Formation Mechanism of Consumer Product Attitude in Online Infomediary. PACIS 2008 Proceedings. Paper 170. http://aisel.aisnet.org/pacis2008/170

6. $\quad$ Chun-Hsing, Chang (1986). Modern psychology. Taipei: TungHua.

7. Darby, M. R., \& Karni, E. (1973). Free competition and the optimal amount of fraud. Journal of Law and Economics, 16 (April), 67-86.

8. Dodds, W. B., Monroe, K. B. \& Grewal, D. (1991). Effect of Price, Brand and Store Information on buyers' Product Evaluation. Journal of Marketing Research, 18,307-319.

9. Doney, P. M., Cannon, J. P. \& Mullen, M.R. (1998). Understanding the Influence of National Culture on the Development of Trust. Academy of Management Review, 23(3), 601-620.

10. Francis Fukuyama (2001). Trust: The Social Virtues and the Creation of Prosperity. NY.

11. Gefen, D. (2000). E-Commerce: The Role of Familiarity and Trust. Omega, 28(6), 725-737.

12. Institute for Information Industry (2006). http://www.find.org.tw/find/home.aspx?page=many\&id=151. (in Chinese)

13. Institute for Information Industry (2007). http://mic.iii.org.tw/pop/micnews4_op_new.asp?sno=375\&cred=2007/10/8. (in Chinese)

14. Laurent, G., \& Kapferer, J. N. (1985). Measuring Consumer Involvement Profiles. Journal of Marketing Research, 23, 41-53.

15. Maheswaran, D., \& Meyers-Levy, J. (1990). The influence of message framing and issue involvement. Journal of Marketing Research, 27, 361-367.

16. McQuarrie, E. F., \& Muson, M. J. (1987). The Zaichkowsky personal involvement inventory: Modification and extension. Advances in Consumer Research, 14, 61-65.

17. Miyake, N., \& Norman, D. A. (1979). To ask a question one must know enough to know what is not known. Journal of Verbal Learning and Verbal Behavior, 18, 357-364.

18. Morwitz, V.G. \& Schmittlein, D. (1992). Using segmentation to improve sales forecasts based on purchase intent: Which 'intenders' actually buy? Journal of Marketing Research, 29(4), 391-405.

19. Nielsen (2007). http://tw.cn.acnielsen.com/site/news20071011.htm .(in Chinese)

20. Nielsen (2010). http://tw.nielsen.com/news20100628.shtml. (in Chinese)

21. O'Guinn, T. C. \& Faber, R. J. (1989). Compulsive Buying: A Phenomenological Exploration. Journal of Consumer Research, 16,147-157.

22. Park, D. H. \& Lee, J. (2008). eWOM Overload and its Effect on Consumer Behavioral Intention Depending on Consumer Involvement. Electronic Commerce Research and Applications, 7,386-398.

23. Raju, P.S., Lonial, S.C. \& Mangold, W.G. (1995). Differential Effects of Subjective Knowledge, Objective Knowledge, and usage Experience on Decision Making: A Exploratory Investigation. Journal of Consumer Psychology, 4(2), 153-180. 
24. Reynolds, F. D., \& Wells, W. D. (1977). Consumer behavior, NY: McGraw-Hill.

25. Rudell, F. (1979). Consumer Food Selection and Nutrition Information. New York: Prageger.

26. Shneiderman, B. (2000). Designing Trust in to Online Experiences, Communications of the ACM, 43(12), 57-59.

27. Stewart, K.J. (2003) .Trust transfer on the World Wide Web. Organization Science, 14 (1), 5-17.

28. Technorati (2008). http://www.trends.tw/archives/2008/09/24/47. (in Chinese)

29. Wen-Yi Hsu \& Chao-Yun Liang (2007).The Influence of Source Credibility, User's Affection and Involvement on College Student's Belief toward Internet Rumor. Journal of Educational Media \& Library Sciences, 45(1), 99-120.

30. Williamson, O. E. (1985). The economic institutions of capitalism. New York: Free Press.

31. Ya-Hsing Wu, Su-Yueh Chu \& Wen-Chang Fang (2008). An Empirical Study of Trust and TAM-An Example of Online Shopping. Journal of Information Management, 15(1), 123-152.

32. Yu Chen Hsu (2010). The opportunity of the medicine cosmetology product. http://www.itis.org.tw/pubinfo-detail.screen?pubid=33545151. (in Chinese)

33. Zaichkowsky, J. L. (1986). Conceptualizing Involvement. Journal of Advertising, 15(2), 4-14. 
\begin{tabular}{ll} 
International Journal of Management \& Information Systems - Third Quarter $2012 \quad$ Volume 16, Number 3 \\
\hline
\end{tabular}

NOTES 